\title{
Influence of persistent wind scour on the surface mass balance of Antarctica
}

\author{
Indrani Das ${ }^{1 \star}$, Robin E. Bell ${ }^{1}$, Ted A. Scambos ${ }^{2}$, Michael Wolovick ${ }^{1}$, Timothy T. Creyts ${ }^{1}$, \\ Michael Studinger ${ }^{3}$, Nicholas Frearson ${ }^{1}$, Julien P. Nicolas ${ }^{4}$, Jan T. M. Lenaerts ${ }^{5}$ \\ and Michiel R. van den Broeke ${ }^{5}$
}

Accurate quantification of surface snow accumulation over Antarctica is a key constraint for estimates of the Antarctic mass balance, as well as climatic interpretations of ice-core records ${ }^{1,2}$. Over Antarctica, near-surface winds accelerate down relatively steep surface slopes, eroding and sublimating the snow. This wind scour results in numerous localized regions $\left(\leq 200 \mathrm{~km}^{2}\right)$ with reduced surface accumulation ${ }^{3-7}$. Estimates of Antarctic surface mass balance rely on sparse point measurements or coarse atmospheric models that do not capture these local processes, and overestimate the net mass input in wind-scour zones ${ }^{3}$. Here we combine airborne radar observations of unconformable stratigraphic layers with lidar-derived surface roughness measurements to identify extensive wind-scour zones over Dome $A$, in the interior of East Antarctica. The scour zones are persistent because they are controlled by bedrock topography. On the basis of our Dome A observations, we develop an empirical model to predict wind-scour zones across the Antarctic continent and find that these zones are predominantly located in East Antarctica. We estimate that $\sim 2.7-6.6 \%$ of the surface area of Antarctica has persistent negative net accumulation due to wind scour, which suggests that, across the continent, the snow mass input is overestimated by $11-36.5 \mathrm{Gt} \mathrm{yr}^{-1}$ in present surface-massbalance calculations.

Over the interior of East Antarctica, significant spatial variability in snow accumulation results from the temperature inversion and gravity-driven katabatic winds interacting with ice surface topography ${ }^{1,3,7,8}$. These katabatic winds erode and sublimate both drifting snow and snow layers on the ground ${ }^{1}$. Extensive regions of wind-induced zero or near-zero surface mass balance (SMB) have been identified by airborne ice-penetrating radars $^{6}$, satellite remote sensing ${ }^{3}$ and ground traverses ${ }^{1,4,9-14}$. A small fraction of the eroded snow over these regions is redeposited downslope forming dunes or infilling topographic depressions and the rest is sublimated ${ }^{13,14}$. Evaluating this complex deposition process over a low accumulation area such as the interior of East Antarctica is important for improving SMB estimates and annual accumulation from ice cores.

Where the winds completely remove the annual snowfall over the scour zones, increased absorption of short-wave solar radiation and enhanced vapour transport facilitate grain growth and metamorphosis of the near-surface firn layers ${ }^{3,14-16}$. In radar stratigraphy, these buried, metamorphosed layers form unconformable surfaces that represent hiatuses in accumulation. Although previous studies have identified wind-induced regions of near-zero to zero SMB over East Antarctica, ${ }^{1,3,4,9,10,14}$, clear thresholds of the physical parameters creating these zones that can be included in physical models do not exist. Here we use data over Dome A to identify persistent wind-induced ablation of the ice surface and develop physical parameterizations to predict continent-wide distribution of sites where slope-induced wind scour leads to negative SMB.

During the AGAP (Antarctica's Gamburtsev Province) project, a $125,500 \mathrm{~km}^{2}$ area over Dome A was surveyed with airborne icepenetrating radar, lidar and other geophysical instruments ${ }^{17}$. The flight lines were spaced $5 \mathrm{~km}$ apart in the north-south direction with $35-\mathrm{km}$-spaced crosslines. Approximately $200 \mathrm{~km}$ away from the Dome, unconformities indicating an erosional surface appear in the near-surface layers where ice flows over steep bedrock topography (Fig. 1a). The unconformities are bright internal reflectors traceable for $\sim 50 \mathrm{~km}$ that truncate the underlying older strata and are onlapped by the overlying younger layers. Truncation of underlying strata by the unconformity indicates that the wind-scour process continues to ablate the surface after removing the previous year's snow. Unconformities are mapped in 45 flight lines in a $65,800 \mathrm{~km}^{2}$ area over Dome A (Fig. $1 \mathrm{~b}$ and Supplementary Fig. S1). These unconformities are located over steep bedrock topography beneath relatively steep surface topography (Fig. 1b). The length of the unconformities when combined with the regional ice velocity ${ }^{17}$ $\left(\sim 1.7 \mathrm{~m} \mathrm{yr}^{-1}\right)$ indicates that the process has persisted for tens of thousands of years.

The surface projections of the unconformities consistently intersect relatively steep ice surface slopes $(\geq 0.002$ or $2 \mathrm{~m}$ per $1,000 \mathrm{~m}$ ) located within broad regions of increased decimeterscale surface roughness (Fig. 1c; also see Methods). These broad regions include both wind-scour zones and high-accumulation areas. Surface roughness in these broad regions is above the local mean $(0.063 \mathrm{~m})$ owing to the presence of surface features such as sastrugi and dunes. Rougher surfaces increase turbulence in the near-surface air stream that further increases the flux of winddrifted snow and sublimation ${ }^{13}$. On the basis of the evidence for enhanced katabatic winds and the geometry of the unconformities, we interpret the surface projections of the unconformities as windscour zones with negative SMB.

These wind-scour zones form when katabatic winds, accelerated by increasing ice surface slopes, remove all of the surface snowfall.

\footnotetext{
${ }^{1}$ Lamont-Doherty Earth Observatory of Columbia University, Palisades, New York 10964-8000, USA, ${ }^{2}$ National Snow and Ice Data Center, CIRES, University of Colorado at Boulder, Colorado 80309, USA, ${ }^{3}$ NASA Goddard Space Flight Center, Greenbelt, Maryland 20771, USA, ${ }^{4}$ Polar Meteorology Group, Byrd Polar Research Center, and Atmospheric Sciences Program, The Ohio State University, Columbus, Ohio 43210, USA, ${ }^{1}$ Institute for Marine and Atmospheric Research Utrecht, Utrecht University, Princetonplein 5, 3584 CC Utrecht, The Netherlands. *e-mail: indrani@ldeo.columbia.edu.
} 



Figure 1 | Distribution of unconformable internal layers and surface morphology over Dome A. a, Radar image with red arrow indicating an unconformity and truncated older layers. The profile location is shown in b,c (black line). b, Lidar-derived surface elevation, bedrock topography and modelled ice surface velocity along a flight line. The blue rectangle indicates the wind-scour zone. $\mathbf{c}$, Lidar-derived surface roughness overlain on a MODIS image. The brown lines indicate the location of the observed unconformities along the flight lines. High surface roughness is observed over the broad region surrounding the unconformities. $\mathbf{d}$, Study area (red square); ice divides (white lines).

Using the measured surface slope, modelled wind and modelled accumulation at observed wind-scour zones over Dome A, we parameterize the conditions under which wind-scour forms. Here, the modelled wind and accumulation values are 31-year annual means of the $10-\mathrm{m}$ wind and SMB fields from a $27-\mathrm{km}$ resolution version of the Regional Atmospheric Climate Model ${ }^{18,19}$ (RACMO2). We obtain surface slopes from a $1-\mathrm{km}$-resolution digital elevation mode ${ }^{20}$. The actual wavelengths present in the digital elevation model are $3-8 \mathrm{~km}$ on the basis of the satellite track spacing. For slope threshold, we use mean slope in the wind direction (MSWD), a dot product of the mean annual wind vector with the gradient of surface slope $e^{3,13}$. We use MSWD as a threshold because the spatial resolution of mean wind speed in climate models is significantly coarser than the scale of ice sheet topography. As the near-surface winds over much of Antarctica's interior are dominated by katabatic flow, areas of higher MSWD will have a locally higher mean wind speed not captured by climate models ${ }^{15}$. As most of the unconformities form at sites where MSWD $\geq 0.002$, we use this value as our slope threshold (Fig. 2a,b). This slope threshold is consistent with other observations of accumulation hiatuses over East Antarctica ${ }^{3,9}$.

Our atmospheric parameter threshold is a ratio of surface accumulation $(A)$ and wind speed $(W)$ :

$$
C=A / W
$$

On the basis of the distribution of $C$ in the Dome A region (Fig. 2c), we identify two thresholds. The threshold $C_{1}$ is based on the mean of the distribution $\left(C_{1}=6.66\right)$. The upper threshold $\left(C_{2}=9.12\right)$ is the maximum value of the distribution.

We apply the slope (MSWD) and atmospheric parameter thresholds $\left(C_{1}\right.$ and $\left.C_{2}\right)$ based on Dome A observations to predict wind-scour zones over the rest of Antarctica. Continent-wide windscour zones are predicted under the condition that both MSWD $\geq$ 0.002 and $A / W$ ratio $(C) \leq C_{2}$ (or $C_{1}$ ) are simultaneously satisfied (Fig. 3 and Supplementary Fig. S2). The thresholds of $A / W$ ratio $\left(C_{1}\right.$ and $\left.C_{2}\right)$ obtained over Dome $\mathrm{A}$ are valid over a large part of Antarctica and extend to the coast of East Antarctica, indicating the continent-wide applicability of this method. The upper threshold $\mathrm{C}_{2}$ indicates erosion at lower wind speeds or higher accumulation and produces larger areas of predicted wind scour (Fig. 4a).

Where the wind-scour conditions are met, the mean threshold $C_{1}$ predicts wind-scour zones over $2.7 \%$ of the total ice surface area of Antarctica excluding ice shelves whereas the upper threshold $C_{2}$ predicts $6.6 \%$. Both thresholds predict extensive areas of wind scour in the Lambert, Byrd and Recovery Glacier catchments and across the Transantarctic Mountains. Our prediction shows sparse wind-scour zones below 1,000 m a.s.l. in East Antarctica and no persistent wind-scour zones in West Antarctica. Over regions lacking persistent wind scour, the accumulation increases more relative to the wind-speed causing the $A / W$ ratio to exceed both $C_{1}$ and $C_{2}$ thresholds (Fig. 3). Although such areas can have large spatial variability in surface snow accumulation ${ }^{21}$ and temporary wind scour may occur after high katabatic events, the wind-scour zones do not persist. During periods of intense katabatic wind activity, large volumes of snow are both sublimated and transported into the ocean ${ }^{22}$. Our model, based on the average of 31 years of winds and accumulation, does not capture the impact of these storms.

We test the validity of our parameterization and the prediction accuracy of $C_{1}$ and $C_{2}$ by examining stratigraphic unconformities in radar data collected over the Recovery Lakes (Supplementary Fig. S3). A distinct unconformity is present and can be traced for $\sim 40 \mathrm{~km}$ as predicted by the upper threshold $C_{2}$. On the basis of this, we also infer that $C_{2}$ works better than $C_{1}$ for continentwide prediction of wind-scour zones. Over Dome A, the steep surface slopes are associated with thinner ice $(<1,500 \mathrm{~m})$, elevated modelled ice surface velocities (see Supplementary Section and Fig. S4) and steep bedrock topography (Fig. 1c). The length of the unconformities over Dome A and the Recovery Lakes indicates a long-lived process and illustrates the feedback between atmospheric processes and ice dynamics ${ }^{23,24}$.

A comprehensive study combining MODIS (Moderateresolution Imaging Spectroradiometer) surface grain size and RADARSAT backscatter identified $\sim 8 \%$ of the surface area of Antarctica as regions of wind-induced near-zero surface accumulation classified as glaze ${ }^{3}$. Over these regions, high winds and intense temperature cycling harden and glaze the surface while increasing 


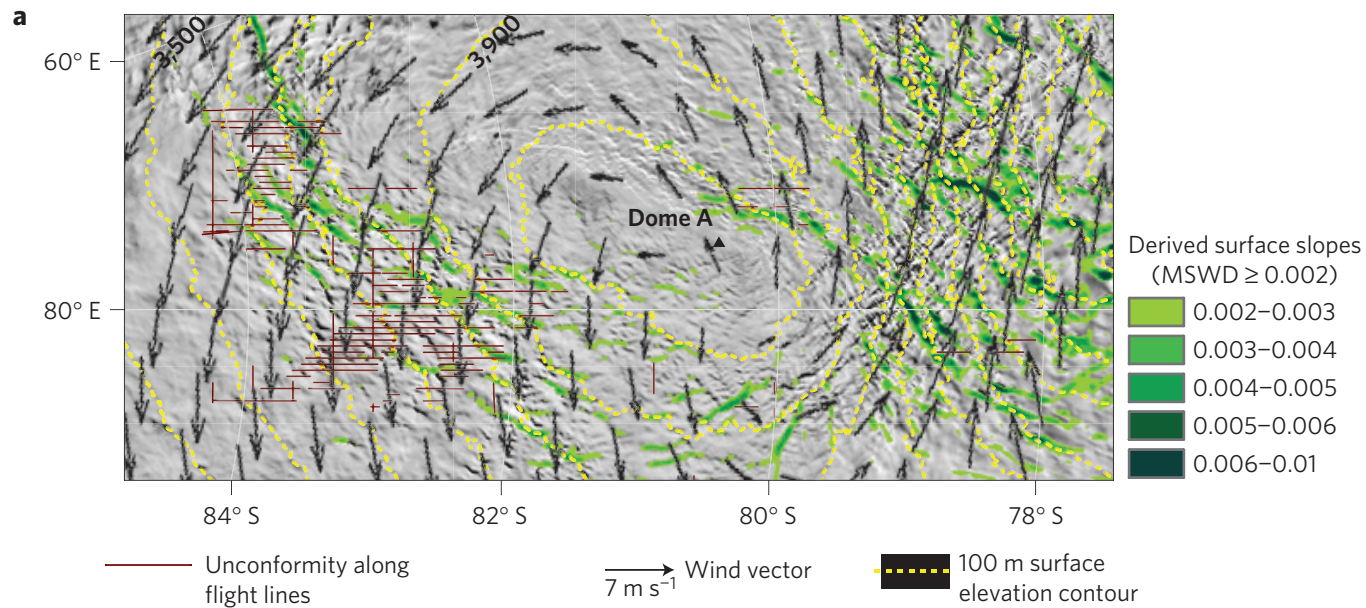

b

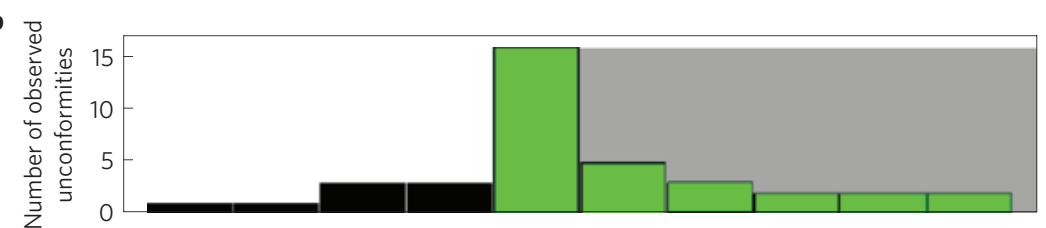

c

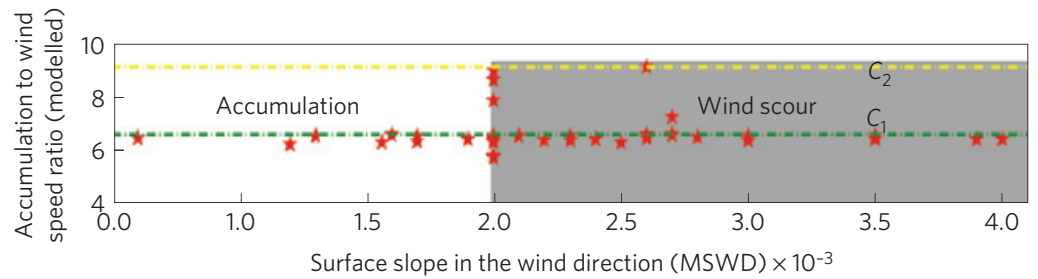

Figure 2 | Slope and atmospheric parameter thresholds for formation of wind-scour zones over Dome A. a, Derived slopes (MSWD $\geq 0.002$ ) over Dome A (green shades), observed unconformities (brown lines) and modelled mean annual near-surface wind vectors (arrows). $\mathbf{b}$, Distribution of the number of observed unconformities as a function of slope (MSWD). c, Accumulation to wind speed (A/W) ratio over the unconformities plotted against MSWD. The dashed green and yellow lines denote, respectively, the mean threshold $\left(C_{1}=6.66\right)$ and the upper threshold $\left(C_{2}=9.12\right)$. The grey shaded region where $M S W D \geq 0.002$ and $A / W \leq C_{2}$ (or $C_{1}$ ) defines where wind scour will form.

the surface and subsurface grain size. Over Dome A, $47 \%$ of the area of predicted wind-scour zones were classified as glaze with large grain size $(>100 \mu \mathrm{m})$ and high radar backscatter $(>-6 \mathrm{~dB})$ (Fig. $4 \mathrm{~b}$ and Supplementary Fig. S5). The glaze distribution, based on high-resolution satellite imagery, captures wind features below the resolution of our threshold method including the East Antarctica megadune fields. Continent-wide, $33 \%$ of the wind-scour zones were classified as glaze, suggesting that sublimation is even more extensive than that predicted by our model. At elevations $<1,500 \mathrm{~m}$ a.s.l. where glaze mapping is difficult, our prediction method resolves $\sim 75 \%$ of the wind scour coincident with observed wind-induced blue ice ${ }^{25}$ (see Supplementary Section and Fig. S5).

These studies identify extensive regions of scour and glaze over the catchments of major East Antarctic glaciers. Together, the predicted wind-scour zones $(6.6 \%$ of surface area) and the additional areas mapped as glaze but not resolved by our method (5.6\%) indicate that $\sim 12.2 \%$ of the surface area of Antarctica is influenced by persistent local wind processes that reduce SMB from the regional mean.

The eroded snow and firn over the wind-scoured zones is either sublimated or redeposited downslope $e^{3,4,12-14}$. The redeposition depends on the curvature of the topographic depressions located downslope of the wind-scour zones ${ }^{4,14,24}$. Larger and deeper topographic depressions can retain more redeposited snow ${ }^{14}$. Sublimation depends mainly on air temperature, MSWD, windspeed and saturation of the near-surface air layers ${ }^{3,12,13}$. As both air temperature and wind speed increase towards the coast, the wind-drifted sublimation rate also increases. Regions with higher MSWD also have higher erosion rates and therefore higher sublimation rates ${ }^{4}$. These sources of sublimation comprise the largest contributor of surface mass loss for Antarctica ${ }^{18,19}$. We estimate mass loss for the wind-scour zones based on fixed and elevation-dependent sublimation rates. Our fixed sublimation rate is based on MSWD and is derived from ground-based observations where $\sim 85 \%$ of surface precipitation is sublimated over steeper surface slopes ${ }^{4}$ (higher MSWD). Assuming $85 \%$ sublimation over wind-scour zones our $C_{1}$ and $C_{2}$ thresholds predict a mass loss of $\sim 11-36.5 \mathrm{Gt} \mathrm{yr}^{-1}$ (Supplementary Section, Table S1 and Fig. S6). Using elevation-dependent sublimation rates from surface traverses ${ }^{4,14}$ over our $C_{2}$-predicted wind-scour zones we estimate a net mass loss of $24.4 \mathrm{Gt} \mathrm{yr}^{-1}$ (see Methods and Supplementary Information). Our wind-scour prediction does not resolve megadune regions where the observed sublimation rate $^{4}$ is $58 \%$ of the surface precipitation. Using the mapped glaze area ${ }^{3}$ over the megadune regions we estimate an additional mass loss of $3.5 \mathrm{Gt} \mathrm{yr}^{-1}$.

This mass loss from both endmember sublimation rates points to an overestimate in all present compilations of Antarctica's SMB. This overestimate of SMB impacts mass-balance estimates using the input-output method ${ }^{26,27}$, especially over those glacier catchments with large concentrations of wind-scour zones. For example, extensive regions of predicted wind scour in the Byrd Glacier 

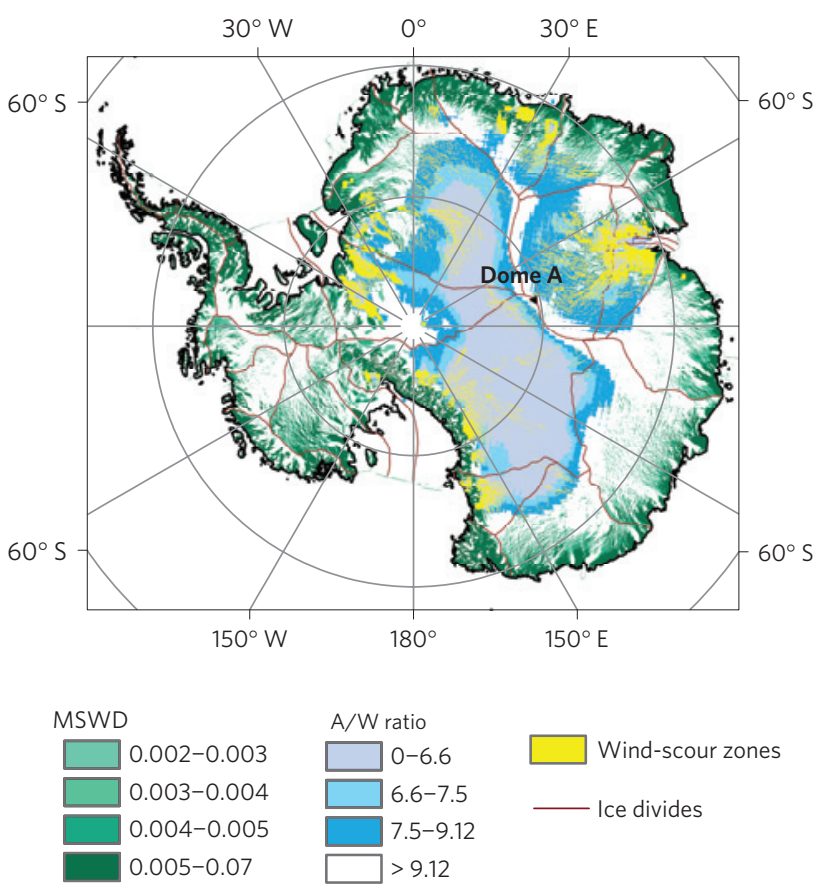

Figure 3 | Continent-wide prediction of wind-scour zones using the $C_{2}$ threshold. Wind-scour zones (yellow) are predicted to form over areas of slope threshold (MSWD $\geq 0.002$ ) and an accumulation to wind speed ratio $(A / W) \leq 9.12$ ( $C_{2}$ threshold $)$. The $A / W$ ratio colour scale shows the continent-wide extent of the $C_{1}(A / W=6.66$, light blue shade $)$ and $C_{2}$ $(A / W=9.12$, dark blue shade) thresholds. The thresholds of $A / W$ ratio from Dome $A$ are consistent over a large section of East Antarctica.

catchment will help to resolve the discrepancy between the positive mass balance estimated by the input-output method ${ }^{27}$ and the nearzero mass balance observed in the Gravity Recovery and Climate Experiment signal ${ }^{28}$. This new prediction of extensive wind scour will improve the SMB compilations and will provide information regarding the spatial variability of surface accumulation for improved interpretation of ice-core records.

\section{Methods}

Elevation-dependent sublimation method. Ground-based observations over Antarctica show that the sublimation rates are high near the coast and decrease towards the interior ${ }^{4}$. Here, we use observed sublimation rates from two overland traverses $^{4,14}$. We grouped the sublimation rates provided by the International Trans Antarctic Scientific Expedition (ITASE) traverse ${ }^{4}$ from Talos Dome to Dome C into three elevation bins on the basis of their proximity to the coast. This traverse measured an average sublimation rate of $82 \%$ of precipitated snow for surface elevations $<2,500 \mathrm{~m}$ a.s.l, $23 \%$ of precipitated snow for surface elevations between 2,500 and 3,000 $\mathrm{m}$ a.s.l and $12 \%$ of precipitated snow for elevations $>3,000 \mathrm{~m}$ a.s.l close to Dome C (red squares in Supplementary Fig. S6). We also group our wind-scour zones into these elevation bins and use the corresponding sublimation rates to estimate mass loss over these zones. A second overland transect, the US-ITASE traverse drove across the Byrd Glacier catchment to the South Pole ${ }^{14}$ and crossed over many of our predicted wind-scour zones (red line in Supplementary Fig. S6). On the basis of their accumulation estimates, their observed percentage of glaze to accumulating regions and assuming a regional average accumulation rate of $0.05 \mathrm{~m}$ water equivalent per year, we determined a sublimation rate of $\sim 26 \%$ of precipitated snow for surface elevations between 2,400 and 2,800 $\mathrm{m}$ a.s.l. This rate is in close agreement with the sublimation rate of $23 \%$ of precipitated snow over 2,500-3,000 $\mathrm{m}$ a.s.l. by the ITASE traverse ${ }^{4}$. Using our $C_{2}$ threshold and the elevation-dependent sublimation rate, our analysis shows a $24.4 \mathrm{Gt} \mathrm{yr}^{-1}$ mass loss over the wind-scour zones (Supplementary Table S1).

Surface roughness. Surface morphology over an ice sheet changes at scales that range from a few centimeters to kilometres ${ }^{29}$. Whereas surface roughness caused by ice dynamics and megadunes is of larger scale and is relatively stable, the decimeter-scale surface roughness caused by sastrugi and other wind-sculpted



b

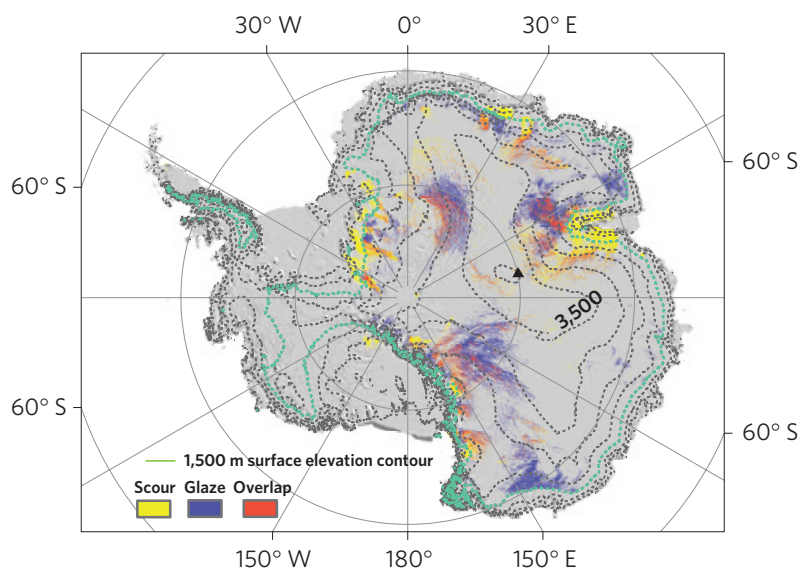

Figure 4 | Wind-scour zones using $C_{1}$ and $C_{2}$ thresholds and comparison with satellite-based observations of surface glaze. a, Predicted wind-scour zones over Antarctica using $C_{1}$ (orange) and $C_{2}$ (yellow) thresholds where $M S W D \geq 0.002$. The area of Antarctica impacted by wind-scour zones is $2.7 \%$ with $C_{1}$ and $6.6 \%$ with $C_{2}$. b. Comparison of $C_{2}$-predicted wind-scour zones with satellite-based surface glaze regions. The figure shows sites with overlapping wind scour and glaze (red), wind scour alone (yellow) and surface glaze alone (blue). Our predicted wind-scour zones extend below the 1,500 m contour (green contour line), the cutoff for glaze observations.

features is transient and sometimes changes within the course of a day. In this study, we have used roughness variations over $200 \mathrm{~m}$ of surface in the horizontal direction to identify the influence of the winds over the Dome A region (Fig. 1c). Here, surface roughness $(S)$ is derived from airborne lidar data collected during the AGAP campaign. As in previous studies ${ }^{29}$, we define surface roughness as the standard deviation of small-scale elevation fluctuations from a moving mean surface elevation over $200 \mathrm{~m}$

$$
S=\operatorname{std} \operatorname{dev}\left(z_{i}-z_{\text {mean }}\right)
$$

We calculate $z_{\text {mean }}$ as the moving mean of 100 lidar shots that cover $\sim 200 \mathrm{~m}$ along the ice surface ( $\sim 2 \mathrm{~m}$ point spacing) and $z_{i}$ is the $i$ th lidar shot along the profile. The standard deviation of this difference gives the surface roughness that is estimated for every flight line. We produce a map by gridding surface roughness at $200 \mathrm{~m}$ (Fig. 1c).

The mean surface roughness of Dome A is $0.063 \mathrm{~m}$ for the $200 \mathrm{~m}$ running mean of surface elevation. Locations on the ice surface exceeding the mean surface roughness are characterized as rough surfaces. Cross-over error analysis to quantify the internal consistency of the lidar data set is provided in Supplementary Fig. S7.

Data sources. AGAP radar and lidar data: ftp://pgg.ldeo.columbia.edu/data/ AGAP/. Also available on request at NSIDC's Antarctic Glaciological Data Center at the University of Colorado, USA. 
Received 16 August 2012; accepted 8 February 2013; published online 31 March 2013

\section{References}

1. Frezzotti, M. et al. Spatial and temporal variability of snow accumulation in East Antarctica from traverse data. J. Glaciol. 51, 113-124 (2005).

2. Arthern, R. J., Winebrenner, D. P. \& Vaughn, D. G. Antarctic snow accumulation mapped using polarization of $4.3-\mathrm{cm}$ wavelength microwave emission. J. Geophys. Res. 111, D06107 (2006).

3. Scambos, T. A. et al. Extent of low-accumulation 'wind glaze' areas on the East Antarctic plateau: Implications for continental ice mass balance. J. Glaciol. 58, 633-647 (2012).

4. Frezzotti, M. et al. New estimations of precipitation and surface sublimation in East Antarctica from snow accumulation measurements. Clim. Dynam. 23, 803-813 (2004).

5. Scarchilli, C. et al. Extraordinary blowing snow transport events in East Antarctica. Clim. Dynam. 34, 1195-1206 (2010).

6. Siegert, M. J., Hindmarsh, R. C. A. \& Hamilton, G. S. Evidence of a large surface ablation zone in central East Antarctica during the last Ice Age. Quat. Res. 59, 114-121 (2003).

7. Jiahong, W. et al. Accumulation variability and mass budgets of the Lambert Glacier-Amery Ice Shelf system, East Antarctica at high elevations. Ann. Glaciol. 43, 351-360 (2006)

8. Parish, T. R. \& Bromwich, D. H. The surface windfield over the Antarctic ice sheets. Nature 328, 51-54 (1987).

9. Watanabe, O. Distribution of surface features of snow cover in Mizuho Plateau. National Institute of Polar Research. Mem. Natl Inst. Pol. Res. 7 (Special issue), 44-62 (1978-01) 1977.

10. Furukawa, T., Kamiyama, K. \& Maeno, H. in Proc. NIPR Symp. Polar Meteorol. Glaciol. Vol. 10, 13-24 (1996).

11. Richardson, C., Aarholt, E., Hamran, S. E., Holmlund, P. \& Isaksson, E. Spatial distribution of snow in western Dronning Maud Land, East Antarctica, mapped by a ground-based snow radar. J. Geophys. Res. 102, 20343-20353 (1997).

12. Frezzotti, M., Urbini, S., Proposito, M., Scarchilli, C. \& Gandolfi, S. Spatial and temporal variability of surface mass balance near Talos Dome, East Antarctica. J. Geophys. Res. 112, F02032 (2007).

13. Frezzotti, M., Gandolfi, S. \& Urbini, S. Snow megadunes in Antarctica: Sedimentary structures and genesis. J. Geophys. Res. 107, 4344 (2002).

14. Arcone, S. A., Jacobel, R. \& Hamilton, G. Unconformable stratigraphy in East Antarctica: Part 1. Large firn cosets, recrystallized growth, and model evidence for intensified accumulation. J. Glaciol. 58, 240-252 (2012).

15. Courville, Z., Albert, M., Fahnestock, M., Cathles, L. \& Shuman, C. Impacts of an accumulation hiatus on the physical properties of firn at a low-accumulation polar site. J. Geophys. Res. 112, F02030 (2007).

16. Shuman, C. A. \& Alley, R. B. Spatial and temporal characterizations of hoar formation in central Greenland using SSM/I brightness temperatures. Geophys. Res. Lett. 20, 2643-2646 (1993).

17. Bell, R. E. et al. Widespread persistent thickening of the East Antarctic Ice Sheet by freezing from the base. Science 331, 1592-1595 (2011).

18. Lenaerts, J. T. M., van den Broeke, M. R., van de Berg, W. J., van Meijgaard, E. \& Kuipers Munneke, P. A new, high-resolution surface mass balance map of Antarctica (1979-2010) based on regional atmospheric climate modeling. Geophys. Res. Lett. 39, L04501 (2012).

19. Lenaerts, J. T. M. et al. Modeling drifting snow in Antarctica with a regional climate model: 1. Methods and model evaluation. J. Geophys. Res. 117, D05108 (2012)
20. Bamber, J. L., Gomez-Dans, J. L. \& Griggs, J. A. A new 1 km digital elevation model of the Antarctic derived from combined satellite radar and laser data-Part 1: Data and methods. The Cryosphere 3, 101-111 (2009).

21. Spikes, V. B., Hamilton, G. S., Arcone, S. A., Kaspari, S. \& Mayewski, P. A. Variability in accumulation rates from GPR profiling on the West Antarctic plateau. Ann. Glaciol. 39, 238-244 (2004).

22. Palm, S. P., Yang, Y., Spinhirne, J. D. \& Marshak, A. Satellite remote sensing of blowing snow properties over Antarctica. J. Geophys. Res. 116, D16123 (2011).

23. Whillans, I. M. Effect of inversion winds on topographic detail and mass balance of inland icesheets. J. Glaciol. 14, 85-90 (1975).

24. Black, H. P. \& Budd, W. Accumulation in the region of Wilkes, Wilkes Land, Antarctica. J. Glaciol. 5, 3-15 (1964).

25. Winther, J-G., Jespersen, M. N. \& Liston, G. E. Blue-ice areas in Antarctica derived from NOAA AVHRR satellite data. J. Glaciol. 47, 325-334 (2001).

26. Rignot, et al. Recent Antarctic ice mass loss from radar interferometry and regional climate modeling. Nature Geosci. 1, 106-110 (2008)

27. Stearns, L. A. Dynamics and mass balance of four large East Antarctic outlet glaciers. Ann. Glaciol. 52, 116-126 (2011).

28. Chen, J. L., Wilson, C. R., Blankenship, D. \& Tapley, B. D. Accelerated Antarctic ice loss from satellite gravity measurements. Nature Geosci. 2, 859-862 (2009).

29. van der Veen, C. J., Ahn, Y., Csatho, B. M., Mosley-Thompson, E. \& Krabill, W. B. Surface roughness over the northern half of Greenland Ice Sheet from airborne laser altimetry. J. Geophys. Res. 114, F01001 (2009).

\section{Acknowledgements}

This work was supported by AGAP-NSF 0632292 (R.E.B., T.T.C., I.D., M.W.), RL-NSF 0636883 (R.E.B., I.D.), IceBridge-NASA NNNX11AC22G (R.E.B.), NSF-OPP 0538103 (T.A.S.) and NASA-NNX10AL42G (T.A.S.). We thank R. Hock, C. Shuman and R. Buck for early reviews of the paper. S. Arcone is acknowledged for helpful discussions. T. Haran, A. Block and H. Abdi are acknowledged for their help in data processing and GIS (geographic information system) support.

\section{Author contributions}

I.D. processed and analysed the lidar data set, interpreted the radar data set, developed the prediction model and wrote the paper. R.E.B. oversaw the field campaign, interpreted the radar data and developed the paper. T.A.S. analysed the atmospheric parameters, provided wind-glaze data and assisted in developing the methodology and the paper. M.W. processed and analysed the radar data set and contributed to velocity modelling. T.T.C. interpreted the radar data set, assisted in methodology and developed the paper M.S. developed the lidar system, processing software and contributed to lidar data processing. N.F. developed the radars and contributed to the processing techniques. J.P.N. helped with interpreting the atmospheric parameters and developed the paper. J.T.M.L. and M.R.v.d.B. provided the RACMO2 and blue ice data set and assisted in interpreting the results. All authors commented on the manuscript.

\section{Additional information}

Supplementary information is available in the online version of the paper. Reprints and permissions information is available online at www.nature.com/reprints. Correspondence and requests for materials should be addressed to I.D.

\section{Competing financial interests}

The authors declare no competing financial interests. 